\title{
El hombre de Cuchipuy* (Prehistoria de Chile Central)
}

\author{
Jorge Kaltwasser, Alberto Medina y \\ Juan Munizaga
}

Cuchipuy es una parte de lo que fuera el gran fundo Taguatagua. Se ubica en la margen norte de la Laguna de ese nombre, hoy desecada, a $7 \mathrm{~km}$ del pueblo de San Vicente de Taguatagua, en la Región del Libertador Bernardo O'Higgins.

El sitio es un cementerio precolombino muy temprano; ocupa ambos costados de un camino que corta un pequeño cerro-isla llamado "El Cerrillo", el cual se separa de un cordón de cerros de baja altura. Diversos cronistas, viajeros y científicos se refirieron a la laguna de Taguatagua, entre otros Alonso de Ovalle (1646), Diego de Rosales (1670), Claudio Gay (1831), Carlos Darwin (1834), James Gilliss (1855), Ignacio Domeyko (1868), elogiando su belleza, vegetación y abundancia de peces y aves.

Los trabajos de desagüe de la laguna comenzaron en 1841 y en el corte practicado con este fin aparecieron restos de fauna pleistocénica, especialmente mastodontes y caballo americano, que despertaron la atención científica tanto en Chile como en el exterior.

En 1967, un grupo interdisciplinario de científicos del Museo Nacional de Historia Natural y la Universidad de Chile excavaron en los cortes del desagüe, a unos $8 \mathrm{~km}$ al Oeste de Cuchipuy, encontrando dos niveles culturales a 1,04 y 2,35 $m$ de profundidad. El primero contenía instrumentos de una industria de cazadores-recolectores que se fechó por R.C. 14 en 6.130 años A.P.; el segundo produjo material lítico en asociación con osamentas de fauna extinta, el que fue fechado por R.C. 14 en 11.380 años A.P. No se encontraron huesos humanos ni paradero relacionado con el material cultural.

Al empezar nuestros trabajos en Cuchipuy, dedujimos que el cementerio

*Este artículo es el resultado de un proyecto de in vestigación que cuenta con la ayuda financiera del Departamento de Investigación y Bibliotecas de la Universidad de Chile. 
debería estar relacionado por lo menos con el nivel de 6.130 años A.P. del desagüe, donde habían aparecido manos de moler, puntas de proyectil, artefactos de hueso, etc.

Después de cuidadosas excavaciones, hemos atribuido los hallazgos de $\mathrm{Cu}$ chipuy a la llamada Etapa Arcaica, lo que se justifica por su posición cronológica y por sus artefactos tan vinculados a esa etapa cultural, que sigue a la Paleo-India o de cazadores de Megafauna. Esta última (12.000 a 9.000 años A.P.) no presenta un patrón de vida sedentario y en el registro arqueológico no se manifiesta un aumento de población. La colecta de productos vegetales parece ser subsidiaria: no hay instrumentos que se relacionen con su aprovechamiento, como son manos, morteros, piedras para moler, etc.

Alrededor de 9.500 años A.P., consecuente con la retirada de los hielos, se produce un aumento de la temperatura y una disminución de la pluviosidad. Comienzan a desaparecer los grandes animales pleistocénicos y empieza a predominar una fauna que podríamos considerar moderna.

El clima más templado hizo posible y necesario que los hombres permanecieran más continuadamente en un lugar que les ofreciera mejores condiciones, limitándose su anterior movilidad. A los instrumentos característicos destinados a cazar y faenar los grandes animales, se agregan ahora artefactos para moler, principalmente alimentos vegetales. Esta etapa se conoce como Paleo-India Tardía o Proto-Arcaica. Con el advenimiento del período climático llamado Altitermal, el de máxima sequedad y calor de los tiempos postglaciales ( $7.000 \mathrm{a}$ 4.000 años A.P.) este modo de vida sufre grandes alteraciones.

Disminuidas las especies que constituían la base de subsistencia (o desaparecidas en algunas regiones) cambiaron las costumbres, adaptándolas a la nueva situación. Es el final del Paleo-Indio y el inicio de la gran etapa Arcaica. El hombre se hizo cazador-recolector, explotando todo el espectro de recursos animales y vegetales. Los sitios del Arcaico tienen como elemento predominante las piedras de moler y los morteros, lo que indica un aprovechamiento intensivo de productos vegetales - semillas, frutos duros, raíces - que son transformados en alimentos digeribles, triturándolos, majándolos o convirtiéndolos en harinas para hacer mazamorras, bebidas espesas o panes. Las piedras para moler posiblemente se empleaban también para reducir a pasta los huesos de animales pequeños, como aves, roedores y batracios.

Se hace un uso óptimo del medio ambiente; caza de animales grandes y caza intensiva de animales pequeños; recolección estacional de especies vegetales, acompañada de técnicas particulares de cocina (piedras calientes) y de almacenamiento en depósitos subterráneos. Aquí, en Cuchipuy, se fabrican instrumentos líticos, de hueso y concha: puntas líticas sin pedúnculo y de base recta o ligeramente cóncavas, como también cuchillos y raspadores; cuentas de piedra y concha, pendientes de piedra y leznas de hueso con puntas aguzadas o tipo formón. En esta etapa encontramos piedras horadadas in situ, dentro de un 


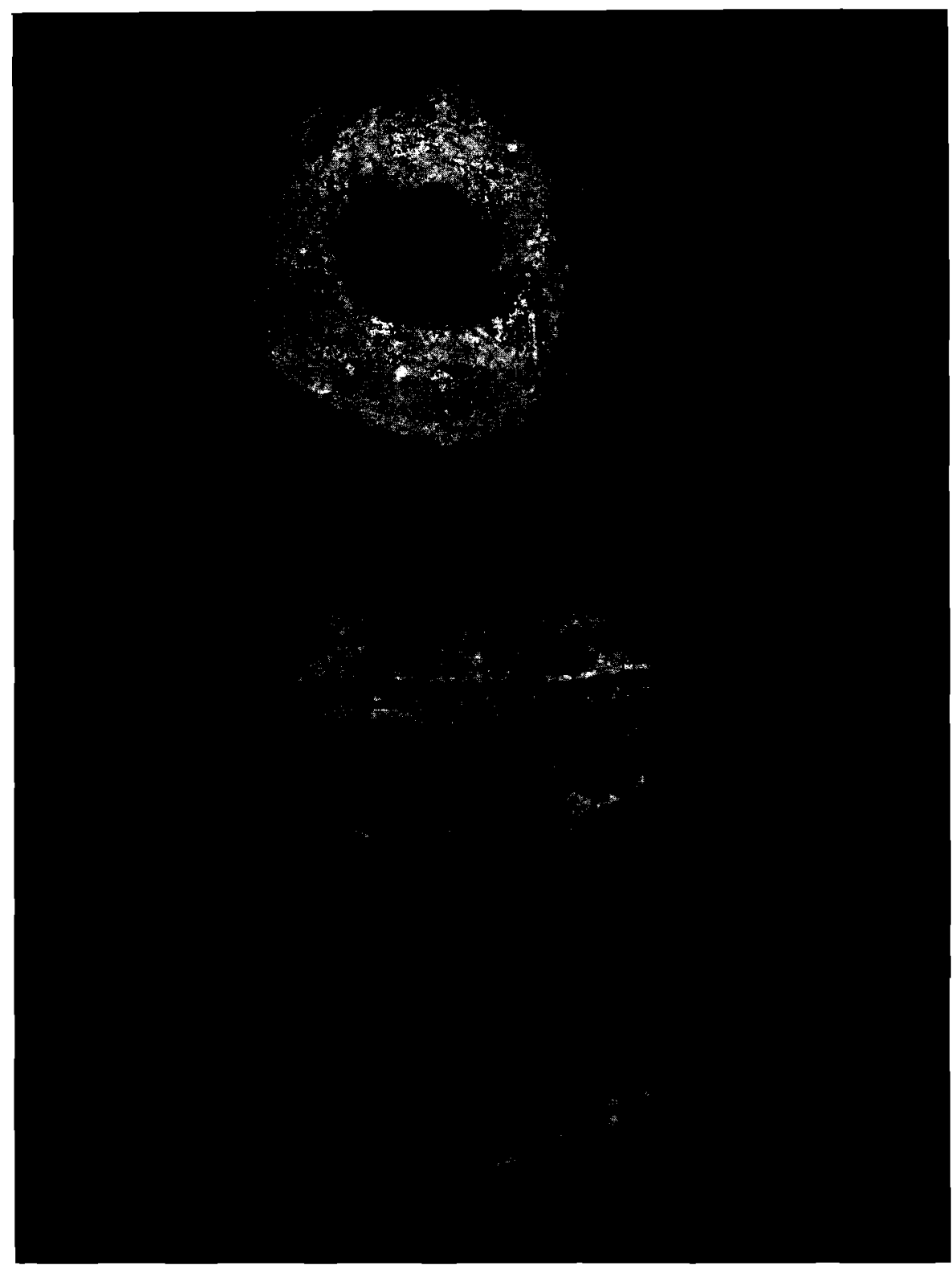

Foto 1. Cuchillo aserrado monofacial, hecho en una grande y delgada lasca (Estrato 3). lnstrumento espeso con canal central para desgastar y pulir artefactos de hueso (Estrato 3).

Piedra horadada (R.C.14, 5.760 años A.P.) (Estrato 2).

Tamaño de los objetos disminuidos en $14 \%$. 


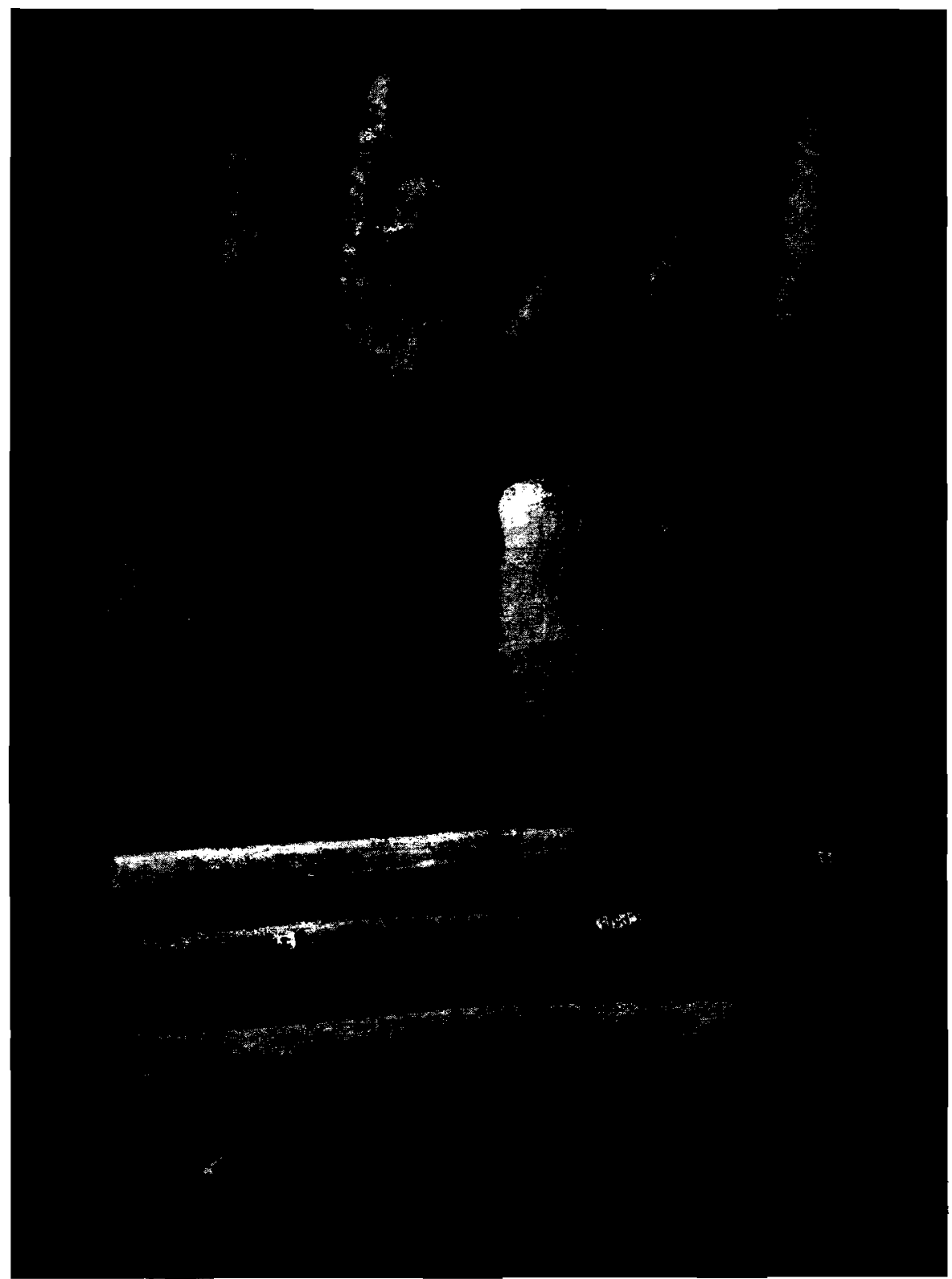

Foto 2. Puntas pedunculadas (Estrato 4). Leznas de hueso (Estratos 2 y 3). Dos talones de Estólica, abajo y a la derecha de la foto (Estratos 2 y 3 ).

Tamaño de los objetos disminuidos en $14 \%$. 
contexto fechado en 5.760 años A.P., fecha que es la primera dada en Chile para estos artefactos.

Los hombres del Arcaico viven muy bien ajustados a los microambientes que constituyen sus diversos habitat, a diferencia de los Paleo-Indios cuyo inmenso espacio geográfico se hallaba circunscrito a los dilatados movimientos de la megafauna.

Hemos sustentado aquí la opinión generalizada en el sentido que el Arcaico se halla "marcado" por la molienda de alimentos, la que se manifiesta en la presencia de morteros y manos de moler desde el comienzo de la etapa.

Sin embargo, si bien hemos estado definiendo el material obtenido en Cuchipuy como Arcaico, debemos consignar que en tres puntos, por lo menos, de las excavaciones, dejan de aparecer en profundidad las piedras de moler y manos, pero continúan los esqueletos humanos, acompañados ahora solamente de una variedad de puntas de proyectil que son más grandes y más toscas, en general, y todas con pedúnculo.

El Geólogo Profesor Juan Varela piensa que la capa estratificada donde se encuentran estos restos esqueletales, sin morteros ni manos para moler, es la misma del Paleo-Indio del desagüe de la laguna. La citada capa fue fechada por R.C. 14 en $8.070 \pm 100$ años A.P. y es la más antigua fecha obtenida por nosotros hasta aquí, la cual estaría en la parte superior del fechado correspondiente al Paleo-Indio de Taguatagua.

Podríamos, entonces, preguntarnos si acaso los niveles más profundos del Cementerio de Cuchipuy no estarían relacionados con el Paleo-Indio descubierto en el desagüe.

La asombrosa continuidad durante miles de años de este cementerio estratificado, con sus diversos niveles, y la evidencia de la paulatina evolución de la cultura, se explicaría por tratarse de un enclave óptimo, un microambiente privilegiado con tal estabilidad climática, que pudo sostener una población que mantuvo su tipo físico desde el Paleo-Indio, hace unos 11.000 años, hasta la aparición de la cerámica.

A modo de resumen, de esta apretada información, diremos que en Cuchipuy hemos encontrado, hasta ahora, cuatro Cementerios yacentes en forma estratigráfica: el primero, con cerámica y esqueletos con cráneos braquicéfalos; el segundo, que corresponde al Arcaico propiamente tal, con esqueletos que tienen cráneos dolicocéfalos, acompañados de una of renda funeraria compuesta por artefactos líticos, de hueso y de concha, entre los cuales se encuentran piedras para moler, morteros y puntas sin pedúnculos; el tercero, que presenta características de los Cementerios 2 y 4 y, finalmente, el Cementerio cuarto, que tiene esqueletos con cráneos ultradolicocéfalos y la ofrenda funeraria está formada solamente por puntas con pedúnculo. Este Cementerio es el más antiguo de Chile y uno de los tres más importantes del Nuevo Mundo, siendo los otros el de Indian Knoll en Estados Unidos de Norteamérica y el de la costa de la provincia 
de Guayas en Ecuador, correspondientes al final del Paleo-Indio y comienzos del Arcaico.

\section{Bibliografía}

Casamiquela, R.; Montané, J. y Santana, R. Convivencia del Hombre con el Mastodonte en Chile Central. Noticia sobre las investigaciones en la Laguna de Taguatagua. Museo Nacional de Historia Natural. Noticiario Mensual No 132: 1-5. Santiago, 1967.

IMBELLoNi, J. 1938. Tabla clasificadora de los Indios, regiones biológicas y grupos raciales humanos en América. Physis, Vol. 12, No 44, 1938 (pp. 229-249).

Kaltwasser, J.; Medina, A. y Munizaga, J. 1980. Cementerio del Periodo Arcaico en Cuchipuy. En Revista Chilena de Antropología No 3, Santiago, 1980 (pp. 109 a 123).

Stewart, T.D. y Newman, M.'T. Anthropometry of South American Indians Skeletal Remains. Handbook of South American Indians. Vol. VI. Smithsonian Institution. 1950.

Tamers, M. y Pearson, F.J. Validity of Radio carbon dates on bones. Nature. Vol. 208, 1965 (pp. 1053-1055). 